ORIGINAL ARTICLE

\title{
Long driving time is associated with haematological markers of increased cardiovascular risk in taxi drivers
}

\author{
J-C Chen, Y-J Chen, W P Chang, D C Christiani
}

Occup Environ Med 2005;62:890-894. doi: 10.1136/oem.2005.020354

See end of article for authors' affiliations

Correspondence to:

Assistant Professor J-

C Chen, Department of

Epidemiology, School of

Public Health, University of

North Carolina, $\mathrm{Rm}$

2104G, McGavran-

Greenberg, CB\# 7435,

Chapel Hill, NC 27599,

USA, USA; icchen@

unc.edu

Accepted 24 June 2005

\begin{abstract}
Aims: To examine the association between driving time and changes in haematological markers of increased risks for cardiovascular diseases (CVD).

Methods: The authors conducted a cross sectional analysis of baseline data from the Taxi Drivers' Health Study cohort in Taipei, Taiwan. They retrieved information on comorbidity, laboratory tests, age, and anthropometric measures from medical records of 1157 subjects (mean age 44.6 (SD 8.6) years). Whole blood cell (WBC) count was used as the primary haematological marker for increased CVD risk, and platelet count and haematocrit as the secondary markers. Standardised questionnaires were implemented to collect information on demographics, lifestyle, work related physical and psychosocial factors, and driving time profiles. Multiple regression was used to estimate the adjusted effects of driving time on three haematological markers.

Results: The mean measured hematological marker was 6656 (SD 1656) cells $\times 10^{6} / \mathrm{l}$ for WBC, 47.2 (SD 3.5 ) \% for hematocrit, and 243 (SD 52) cells $\times 10^{9} /$ for platelets. The driving time was 264 (SD 76) hours/month. Compared with drivers who drove $\leqslant 208$ hours/month (1 st quartile cut off), drivers who drove $>208$ hours/month had a higher WBC count (by $317 \times 10^{6} / 1 ; 95 \% \mathrm{Cl} 99$ to 535 ), haematocrit (by $0.8 \% ; 95 \% \mathrm{Cl} 0.3$ to 1.2 ), and platelets $\left(7.9 \times 10^{9} / \mathrm{l} ; 95 \% \mathrm{Cl} 1.0\right.$ to 14.8$)$. After adjusting for conventional CVD risk factors (age, sex, smoking, hypertension, diabetes, and hypercholesterolaemia), obesity, alcohol drinking, regular exercise, and sociodemographics (education, marital status, income, and so on), long driving time was still associated with significant increases in WBC and platelets, whereas the effect on haematocrit was diminished and became statistically non-significant. Additional controls for physical workload, self-perceived job stress, and job dissatisfaction did not alter the associations with increased WBC and platelets.

Conclusions: Longitudinal studies are needed to confirm the observed cross sectional association and to further examine the specific occupational exposures accountable for the association between driving time and haematological markers of systemic inflammation and haemostatic alteration.
\end{abstract}

C ardiovascular diseases (CVD) of professional drivers remain an important issue in occupational health research and clinical practice. For decades, occupational epidemiological studies have provided a large body of consistent evidence showing that professional drivers are at high risk for CVD. High morbidity and mortality related to coronary artery diseases ${ }^{1-4}$ and cerebrovascular events ${ }^{5}$ have been found among professional drivers. Using a population based hospital discharge registry of myocardial infarction (MI), Bigert et al ${ }^{6}$ compared the relative risk (RR) of $\mathrm{MI}$ among professional drivers in Stockholm County, Sweden, during both 1977-84 and 1985-96. They found that, compared with manual workers, taxi drivers and lorry operators had an increased MI risk which persisted throughout the entire study period (with corresponding RR of 1.38 and 1.35 among taxi drivers and both of 1.14 among lorry drivers during each period). Their data suggested that, although CVD incidence in professional drivers has been decreasing since the 1970s, existing preventive measures seemed to have only little effect on the excessive CVD risk directly imparted by occupational factors involved in driving. This disturbing time trend also underscores the needs for a better understanding of work related CVD among professional drivers

In spite of the convincing epidemiological data, the underlying mechanisms linking professional driving to increased CVD risks remain unclear. Earlier studies in the 1980s suggested that some conventional risk factors, such as smoking and hypercholesterolaemia, were more prevalent among professional drivers and accounted for their increased risk for $\mathrm{CVD}^{78}$ Later studies have mostly refuted this speculation and revealed an increased CVD risk independent of conventional risk factors among drivers. In their prospective study in Gothenburg, Rosengren et al demonstrated that the excess risk of coronary heart disease among middle aged bus and tram drivers was independent of conventional CVD risk factors, as the RR was only diminished slightly (from 3.3 to 3.1) after controlling for major cardiac risk factors. Similar findings were also reported among bus and taxi drivers. ${ }^{4}$

Researchers have begun to examine more specific pathophysiological changes related to CVD among professional drivers, ${ }^{10}$ and a few neuroendocrine and neuroelectrophysiological pathways have been investigated. For example, studies have demonstrated that various driving related activities, such as physical loading, mechanised work, traffic congestion, long distance driving, might result in increased urinary excretion of catecholamine, ${ }^{11}{ }^{12}$ increased cortisol level, ${ }^{13} 14$ and decreased heart rate variability. ${ }^{15}{ }^{16}$ These neurocardiological responses are all plausible mediators as they may exert a transient effect on the cardiovascular system or amount to significant cardiac risk over a long period. However, the sample size of most of these studies was small,

Abbreviations: $\mathrm{BMI}$, body mass index; $\mathrm{CBC}$, complete blood count; CVD, cardiovascular diseases; TDHS, Taxi Drivers' Health Study; WBC, white blood cell 
and potential confounding by other concurrent CVD risk factors was not adequately addressed.

Enormous progress made during the past few decades has dramatically enhanced our understanding of the pathophysiology responsible for CVD. Investigations in vascular biology have pointed to a central role of inflammation in the initiation and progression of atherosclerosis. ${ }^{17-19}$ Whether inflammation and haemostatic alteration are also involved in the increased CVD of professional drivers has not been very well studied. In the current study, we aimed to examine the association between driving time and haematological markers of increased CVD risks. We hypothesised that the levels of haematological markers of CVD risks increased with driving time.

\section{METHODS}

\section{Study population}

The study population was the baseline cohort of the Taxi Drivers' Health Study (TDHS) in Taipei City, Taiwan. Details about the design of TDHS have been described elsewhere. ${ }^{20} 21$ In brief, in 2000 the Taipei City Government designated five hospitals to provide taxi drivers with free physical examinations. Between January 31 and May 31, 3295 taxi drivers participated in this medical monitoring programme, and the TDHS subjects came from the hospital with the largest assigned service volume. We previously reported that TDHS participants were a representative sample of taxi drivers in Taipei City and their baseline characteristics of TDHS participants were not systemically different from those receiving medical examinations in other hospitals. ${ }^{20}$ The main outcomes of research interest at the design phase of TDHS included cardiovascular disease risks, job stress, and musculoskeletal disorders, among others. For drivers to be eligible for enrollment in the TDHS, they had to have been: (a) registered taxi drivers in Taipei City for at least one year, (b) willing to participate, and (c) able to read. The research protocols and consent forms were approved by the institutional review board of the Taipei Veterans General Hospital, Taipei, Taiwan. Informed consent was obtained from every TDHS participant in the selected hospital.

\section{Outcome measures}

Data on the haematological markers were retrieved from the laboratory blood routines which included complete blood count (CBC), fasting blood sugar, and other clinical biochemistries. Although previous studies have linked CVD risks to increased white blood cells (WBC) count, $^{22-24}$ haematocrit, ${ }^{25}$ and platelets count, ${ }^{26}$ findings on the increased CVD risks and adverse CVD outcomes associated with high WBC counts were more consistent than those studies on haemotocrit and platelet counts. ${ }^{27}$ Therefore, we used WBC as the primary haematological marker of increased CVD risks, and the other two as the secondary marker. The CBC test was performed in the clinical laboratory at the selected hospital by an Automated Hematology Analyzer (SE-9000, Sysmex Corp, Kobe, Japan) following conventional validated methods.

\section{Measurement of covariates}

We developed a standardised self-administered instrument to measure personal characteristics and occupational factors in this study. The feasibility of this instrument was tested in a convenience sample of drivers before the study began. In addition to data on demographics and lifestyle factors (smoking, alcohol drinking, exercise), the questionnaires consisted of items for professional seniority in years, monthly driving duration in hours, and average frequency of physical workload (lifting task and bending/twisting) at work and during leisure time. Previous studies have found that self reporting is a relatively reliable and valid method to assess the time spent in driving. ${ }^{28}{ }^{29}$ In a small subset of baseline data from drivers who also participated in an exposure assessment study, ${ }^{30}$ we also found that self-reported monthly driving time was fairly reliable (Pearson's correlation coefficient $=0.79$ ), in comparison with data from driving diaries records and structured interviews. Age, sex, anthropometric measures (body weight and height), measures of blood pressure, and results of other relevant laboratory tests were also retrieved from the medical examination files. Drivers were classified as diabetics if they had fasting sugar $>126 \mathrm{mg} / \mathrm{dl}$ or physician diagnosed diabetes with subsequent treatment. Hypertension was defined as either measured systolic/diastolic blood pressures $\geqslant 140 / 90 \mathrm{~mm} \mathrm{Hg}$ or physician diagnosed hypertension with subsequent treatment. Drivers were also classified as having normal $(<200 \mathrm{mg} / \mathrm{dl})$, borderline high $(200-239 \mathrm{mg} / \mathrm{dl})$, or high ( $\geqslant 240 \mathrm{mg} / \mathrm{dl})$ total cholesterol. LDL and HDL cholesterol levels were not measured. Body mass index (BMI) was used to evaluate whether drivers were normal $\left(\mathrm{BMI}<24 \mathrm{~kg} / \mathrm{m}^{2}\right)$, overweight (BMI $\left.24-26.9 \mathrm{~kg} / \mathrm{m}^{2}\right)$, or obese $\left(\mathrm{BMI} \geqslant 27 \mathrm{~kg} / \mathrm{m}^{2}\right){ }^{31}$

\section{Statistical analysis}

We used multiple regression to estimate the effect of monthly driving time on haematological markers of CVD risk. We grouped drivers into four categories according to the quartile distribution of total hours of taxi driving per month. For a covariate to be considered in the final model, it must have resulted in at least a $10 \%$ change in the regression coefficient representing effect of driving on haematological markers or each covariate should be statistically significant at the 0.2 level in the univariable analysis. In order to make statistical inference conditional on all established CVD risk factors, we included age, sex, smoking (non-smoker $v$ ex-smoker $v$ current smoker), hypertension, diabetes, and hypercholesterolaemia (normal $v$ borderline high $v$ high) in the final model, regardless of their levels of statistical significance in the univariable analyses. We assumed no interaction terms among potential predictors, and only included cases with complete data information in the final analyses. All of these statistical analyses were carried out by STATA 7.0 statistical software (STATA Corporation, College Station, TX, USA). The distribution of residuals calculated for presented final models conformed to the normality assumption for each of three dependent variables.

\section{RESULTS}

During the study period for collecting baseline TDHS data, of the 1355 drivers receiving medical examinations in the selected hospital, 1242 (92\%) participated in the questionnaire survey, and 1192 (89\%) had complete information on both driving time and routine $\mathrm{CBC}$ data. Thirty five subjects with WBC $>12000$ or $<3500$ cells $\times 10^{6} /$, which likely reflected some acute pathological processes or underlying diseases, were excluded, thus leaving 1157 (mean age 44.6 (SD 8.6) years) eligible for the analyses. The measured haematological marker was 6656 (SD 1656) cells $\times 10^{6} / 1$ for WBC, 47.2 (SD 3.5) \% for haematocrit, and 264 (SD 76) cells $\times 10^{9} / 1$ for platelets. The majority $(52 \%)$ of drivers had been professional taxi drivers for more than 10 years. The mean driving time per month was 264 (SD 76) hours, corresponding to approximately 10 (SD 2) hours per day and 26 (SD 2 ) days per month. Forty two per cent $(42 \%)$ were current smokers, $35 \%$ were overweight, and $24 \%$ were obese. The prevalence of hypertension, diabetes, and hypercholesterolaemia (total cholesterol $>240 \mathrm{mg} / \mathrm{dl}$ ) was $15 \%, 12 \%$, and $32 \%$ respectively.

In the crude analyses, monthly driving time was associated with all three haematological markers of increased CVD risks (table 1). Compared with drivers who drove $\leqslant 208$ hours/ month ( lst quartile cut off), drivers who drove $>208$ hours/ 
Table 1 The average white blood cells (WBC) count, haematocrit, and platelet count, and their associations* with driving time in Taxi Drivers' Health Study, Taipei, Taiwan

\begin{tabular}{|c|c|c|c|c|c|c|}
\hline Monthly driving time (hours) & $\begin{array}{l}\text { WBC count (cells } \\
\left.\times 10^{6} / \mathrm{l}\right) \dagger\end{array}$ & $\begin{array}{l}\text { Adjusted } \ddagger \text { regression } \\
\text { coefficients }\end{array}$ & $\begin{array}{l}\text { Haematocrit } \\
(\%) \dagger\end{array}$ & $\begin{array}{l}\text { Adjusted§ regression } \\
\text { coefficients }\end{array}$ & $\begin{array}{l}\text { Platelets count } \\
\left(\text { cells } \times 10^{9} / \mathrm{l}\right) \dagger\end{array}$ & $\begin{array}{l}\text { Adjusted } 9 \text { regression } \\
\text { coefficients }\end{array}$ \\
\hline 1st quartile ( $\leqslant 208$ ) & $6420(1599)$ & Reference & $46.6(3.6)$ & Reference & $236.9(50.6)$ & reference \\
\hline 2nd quartile (210-260) & $6680(1686)$ & $264(-2$ to 529$)$ & $47.2(3.7)$ & $0.3(-0.3$ to 0.8$)$ & $241.9(53.9)$ & $2.7(-6.4$ to 11.8$)$ \\
\hline 3rd quartile (261-312) & 6733 (1671) & $278(20 \text { to } 539)^{* *}$ & $47.3(3.1)$ & $0.1(-0.5$ to 0.6$)$ & 245.5 (51.7) & $7.5(-1.4$ to 16.4$)$ \\
\hline 4th quartile (318-450) & 6799 (1652) & $285(16 \text { to } 555)^{\star \star *}$ & $47.6(3.3)$ & $0.4(-0.1$ to 1.0$)$ & 246.9 (53.4) & $9.6(0.3 \text { to } 18.9)^{* *}$ \\
\hline ( $p$ value for trend test) & 0.006 & 0.04 & 0.001 & 0.24 & 0.01 & 0.02 \\
\hline
\end{tabular}

*All regression coefficients obtained from multiple regression were expressed as the difference in average levels of haematological markers between the reference and the indicated categories.

†Results shown as mean (standard deviation).

†Adjusted for age, sex, marital status, education, registration type, exercise frequency, alcohol drinking, BMI, smoking, hypertension, diabetes, and hypercholesterolaemia.

§Adjusted for age, sex, professional seniority, marital status, income, registration type, BMI, smoking, hypertension, diabetes, and hypercholesterolaemia.

-Adjusted for age, gender, marital status, education, income, registration type, BMI, smoking, hypertension, diabetes, and hypercholesterolaemia.

${ }^{* *} p<0.05$.

month had a higher WBC count (by 317 cells $\times 10^{6} / 1$; $95 \%$ CI 99 to 535 ), haematocrit (by $0.8 \%$; $95 \%$ CI 0.3 to 1.2 ), and platelet count $\left(7.9 \times 10^{9} / 1 ; 95 \%\right.$ CI 1.0 to 14.8$)$. We noted that such an increase in WBC count was not predominated by any specific cell type, since the proportions of increased neutrophils $(60 \%, p=0.02)$, monocytes $(7 \%, p=0.05)$, and lymphocytes $(30 \%, p=0.05)$ were comparable with the usual haemogram. The univariable regression also revealed that, for drivers who were unmarried, beyond high school education, less engaged in strenuous exercise, or affiliated with taxi cab companies, the WBC counts were higher than those of their counterparts (all p values $<0.07$ ). The average WBC count of drivers with normal BMI $\left(6531 \times 10^{6}\right)$ was lower than average WBC count of overweight $\left(6703 \times 10^{6}\right)$ or obese drivers $\left(6802 \times 10^{6}\right)$. The WBC count did not differ significantly by professional seniority.

The presence of conventional CVD risk factors except age was associated with high WBC counts of taxi drivers in the univariable analyses (table 2). Active smokers had statistically significant higher WBC counts than past smokers and those who never smoked. Female drivers had lower WBC count than male drivers. Hypertension, diabetes, and hypercholesterolaemia were all associated with increased WBC counts in taxi drivers. In the multiple regression model which included the main effect of monthly driving time adjusting for age, marital status, education, registration type, regular exercise, BMI, and all the other conventional CVD risk factors, higher WBC count was consistently associated with smoking, hypertension, diabetes, and hypercholesterolaemia.

Additional analyses were conducted to evaluate residual confounding and to examine whether the observed long driving time/WBC count association could be explained by work related physical or psychosocial factors. Firstly, the modest but positive correlation between driving time and number of cigarettes used (Spearman's $r=0.14, \mathrm{p}=0.01$ ) prompted us to evaluate the residual confounding by the amount of cigarette smoking. We found that WBC count increased with the amount of cigarette smoking: each 10 cigarettes smoked per day was associated with an increase in WBC count by 423 cells $\times 10^{6} / 1$ among active smokers. Even after adjusting for the amount of active cigarette smoking, those who drove more than 208 hours per month had significantly higher WBC count (increased by 458 cells $\left.\times 10^{6} / 1\right)$ than divers who drove 208 hours or less. Secondly, we additionally included variables representing the frequency of physical workload (lifting task and bending/twisting) at work, and self-reported job stress perception and job dissatisfaction index, which were derived from the validated Chinese version of Job Content Questionnaire. ${ }^{32}$ None of the physical workload was associated with WBC count. In the multiple regression, job dissatisfaction index did not affect WBC count, although a marginal increase in WBC count was noted among those in the highest quartile $(p=0.09)$. In contrast, self-perceived job stress was associated with WBC count $(p=0.02)$. Compared with drivers reportedly with no perceived stress, the WBC count increased by 198 (95\% CI -46 to 442 ) cells $\times 10^{6} / 1$ for drivers with mild job stress and by $333\left(95 \%\right.$ CI 53 to 612 ) cells $\times 10^{6} / 1$ for drivers perceiving moderate to severe job stress. Additional adjusting for selfreported physical workload and work related psychosocial factors did not alter the association between long driving time and high WBC count. Compared with the average WBC count of drivers who drove 208 hours/month or less, drivers

Table 2 The average white blood cells (WBC) count in relation to conventional risk factors for cardiovascular diseases (CVD)

\begin{tabular}{|c|c|c|}
\hline CVD risk factors & $\begin{array}{l}\text { WBC count (cells } \\
\left.\times 10^{6} / \mathrm{l}\right)^{*}\end{array}$ & $\begin{array}{l}\text { Adjusted regression } \\
\text { coefficients }^{*} \dagger\end{array}$ \\
\hline \multicolumn{3}{|l|}{ Smoking } \\
\hline Never smokers & $6122(1360)$ & Reference \\
\hline Ex-smokers & 6469 (1498) & $412(123$ to 700$) \ddagger$ \\
\hline Current smokers & 7259 (1776) & 1204 (999 to 1409$) \ddagger$ \\
\hline \multicolumn{3}{|l|}{ Sex } \\
\hline Female & 6132 (1642) & Reference \\
\hline Male & $6678(1654)$ & $41(-443$ to 525$)$ \\
\hline \multicolumn{3}{|l|}{ Hypertension } \\
\hline No & 6605 (1637) & Reference \\
\hline Yes & 6937 (1734) & 439 (175 to 703$) \ddagger$ \\
\hline \multicolumn{3}{|l|}{ Diabetes } \\
\hline No & $6610(1666)$ & Reference \\
\hline Yes & 6991 (1547) & 346 (65 to 627)§ \\
\hline \multicolumn{3}{|l|}{ Total cholesterol } \\
\hline Normal & 6475 (1567) & Reference \\
\hline Borderline high & $6641(1683)$ & $161(-61$ to 384$)$ \\
\hline High & 6854 (1693) & 372 (137 to 606$) \ddagger$ \\
\hline
\end{tabular}

*All the differences in average WBC counts across categories of each risk factor were statistically significant $(p<0.05)$. All regression coefficients obtained from multiple regression were expressed as the difference in average levels of haematological markers between the reference and the indicated categories.

†Adjusted for age, sex, marital status, education, registration type, exercise frequency, alcohol drinking, body mass index, monthly driving duration, and all the other CVD risk factors in the table.

$\neq \mathrm{p}<0.01$.

$\S p<0.05$.

Diabetes: fasting sugar $>126 \mathrm{mg} / \mathrm{dl}$ or physician diagnosed diabetes with subsequent treatment; hypertension: systolic/diastolic blood pressures $\geqslant 140 / 90 \mathrm{~mm} \mathrm{Hg}$ or physician diagnosed hypertension with subsequent treatment; total cholesterol: classified as normal ( $<200 \mathrm{mg} /$ dl), borderline high (200-239 mg/dl), or high ( $\geqslant 240 \mathrm{mg} / \mathrm{dl}$ ). 
with driving time longer than 208 hours/month had a statistically significant $(\mathrm{p}=0.03)$ increase in the WBC count by 241 ( $95 \%$ CI 23 to 459$)$ cells $\times 10^{6} / 1$.

\section{DISCUSSION}

Our cross sectional study provided the first epidemiological data suggesting the involvement of increased inflammation and altered haemostasis in CVD of taxi drivers. We demonstrated that haematological markers of increased cardiovascular risks were associated with long driving time, and such association could not be attributable completely to the conventional CVD risk factors. The consistent driving related increase in WBC count highlighted an associated inflammatory responses involved either in the development or progression of CVD in taxi drivers. Adhesion of circulating leukocytes has been known to be one of the earliest morphological events in the development of atherosclerotic plague. Indeed, large population based cohort studies, such as the Framingham Heart Study ${ }^{22}$ and Atherosclerosis Risk in Communities (ARIC) Study, ${ }^{23}$ have reported an increase in long term CVD risk associated with high WBC count. Recruitment, activation, and infiltration of inflammatory leukocytes have significant contributions to plaque rupture. Also, clinical investigations have indicated that patients with an increased WBC count have an increased early (30 day) mortality following $\mathrm{MI}^{33}$ or acute coronary syndrome. ${ }^{34}$

Which specific occupational exposures might account for the observed association between long driving time and the presumed inflammatory marker of increased CVD risk in taxi drivers? Urban taxi drivers are regularly exposed to a variety of physical (for example, physical workload, traffic noise, whole body vibration) and chemical hazards (for example, carbon monoxide, vehicle exhaust) and work related psychosocial factors (for example, job stress, night-time driving), which have all been considered detrimental for cardiovascular health. The existing evidence on physical workload/CVD relation is mixed; ${ }^{35} 36$ our analyses did not reveal any association of WBC count with work related physical load (lifting, bending, and/or twisting) in Taipei taxi drivers. The observed association between self perceived job stress and WBC count conforms to the notion that work related psychosocial stressors may promote inflammatory responses and culminate in atherosclerosis. ${ }^{37}{ }^{38}$ In spite of the likelihood of residual confounding by other psychosocial domains of job stress, given the statistical significance which remained after adjusting for the work related psychosocial factors in the multiple regression, our data might imply that the observed driving time/WBC count association perhaps involved other important occupational factors. Nevertheless, we did not measure drivers' exposures to vehicle exhaust, although convincing data from environmental studies have shown that exposures to particulate air pollution in urban environment are associated with increased WBC count. ${ }^{39} 40$ Further studies are needed to identify the specific occupational exposures with the most significant contribution to systemic inflammation and altered haemostasis, and differentiate their relative and joint effects on the CVD of professional drivers.

Among the TDHS participants, conventional CVD risk factors constituted an important portion of the inflammation associated increase in cardiac risk, as smoking, hypertension, diabetes, and hypercholesterolaemia were all positively associated with WBC count (table 2). This finding was consistent with other clinical investigations and supported the central role of inflammation underlying the process of atherosclerosis contributed by each conventional CVD risk factor. ${ }^{41}{ }^{42}$ Many previous studies have found that professional drivers had a high prevalence of conventional CVD risk factors, which had been implicated in the intermediates between driving and CVD. ${ }^{7}$ Compared with the national estimates for Taiwanese men aged $45-64$ years, ${ }^{43}$ male taxi drivers of similar age did have significantly higher diabetes prevalence ( $15.6 \% \vee 7 \%, \mathrm{p}<0.001)$ and total cholesterol level (225.3 (SD 41.4) $v 198.2$ (SD 38.3) mg/dl; $\mathrm{p}<0.001$ ), although the difference in diastolic blood pressure $(85.2$ (SD 12.8) v 84.4 (SD 12.7) $\mathrm{mm} \mathrm{Hg} ; \mathrm{p}=0.14$ ) and active smoking $(43 \% \quad v \quad 44 \% ; \quad \mathrm{p}=0.52)$ were not statistically distinguishable. $^{44}$ In the final multiple regression model, adjusting for these conventional CVD risk factors did downsize the effect of driving time (comparing the 4th and 1st driving time quartile) on WBC count $\left(285 \vee 379 \times 10^{6}\right)$. However, it is noteworthy that the driving time/WBC count association remained statistically significant in the adjusted analysis. Our study results thus reinforced the previous notion that increased frequency of CVD among professional drivers could not be solely explained by the high prevalence of conventional CVD risk factors.

We recognise several limitations to our study. Firstly, because of its cross sectional design, the observed association between long driving time and increased WBC and platelet counts cannot definitely be interpreted as causal. Although we could not provide any good reasons that drivers with high WBC count might have preferred or chosen long driving time, it is statistically arguable that these drivers might happen to have high WBC counts at baseline. Secondly, WBC count is a sensitive but non-specific haematological marker for various physical and psychosocial stressors. Although we have restricted our analyses to those with presumably normal WBC count and also adjusted for many demographical, socioeconomic, lifestyle, and clinical variables, we could not rule out the possibility of unmeasured confounding by nonoccupational sources of mental stress (for example, stressful life events with increased financial needs) which may translate to both long driving time and increased WBC count. Thirdly, high WBC and platelets counts assessed in this study may simply reflect surrogate measures of acute phase reactants (for example, C-reactive protein, fibrinogen) involved in the pathogenesis of CVD; they do not necessarily reflect functional abnormalities with direct involvement in atherosclerosis, such as leukocyte activation, overexpression of leukocyte adhesion molecules, or leukocyte-platelet interaction. Future studies investigating the speculated vascular inflammation and haemostatic alteration in the development and progress of CVD in professional drivers should look into more specific mechanistic measures.

\section{CONCLUSION}

Our study demonstrates that haematological markers of increased cardiovascular risks are associated with long driving time independent of conventional risk factors in taxi drivers. Longitudinal studies are needed to confirm the observed cross sectional association and to further investigate the associations between specific occupational exposures and biomarkers of systemic inflammation and haemostatic alteration.

\section{ACKNOWLEDGEMENTS}

The Taxi Drivers' Health Study was jointly funded by the Institute of Occupational Safety and Health, Council of Labor Affairs, and the Bureau of Transportation, Taipei City Government, Taiwan. The authors appreciate Dr Tung-Sheng Shih and Dr Chiou-Jong Chen of The Institute of Occupational Safety and Health, Taipei, Taiwan, for their administrative help and valuable contribution to the early phase of the TDHS. The authors thank Ms Mei-Shu Wang, Ms Michelle Yen, and Ms Yu-Ping Wu for their assistance in both data collection and research administration. The authors are grateful for Ms Queenie E Lee, Ms Chi-Chia Liang, and Mr Zai-Jung Huang for their contribution to data management. 


\section{Main messages}

- The mechanisms underlying high frequency of cardiovascular disease in professional drivers remain unclear.

- The study provided the first epidemiological data suggesting the involvement of inflammation and haemostatic alteration.

- The consistent association between driving time and high WBC count was independent of conventional CVD risk factors.

\section{Policy implications}

- Longitudinal studies are needed to confirm the observed cross sectional association and to further examine the associations between specific occupational exposures and biomarkers of systemic inflammation and haemostatic alteration.

\section{Authors' affiliations}

J-C Chen, Department of Epidemiology, University of North Carolina, School of Public Health, Chapel Hill, NC, USA

Y-J Chen, Division of Cardiovascular Medicine, Wan Fang Hospital and Department of Medicine, School of Medicine, Taipei Medical University; Taipei, Taiwan

W P Chang, Institute of Environmental Health Science, National YangMing University, Taipei, Taiwan

D C Christiani, Occupational Health Program, Department of Environmental Health, Harvard School of Public Health, Boston, MA, USA

Sponsored by the Institute of Occupational Safety and Health, Taiwan; Bureau of Transportation, Taipei City Government.

The authors declare that they have no conflicts of interests or competing interests related to the publication of this research work.

\section{REFERENCES}

1 Hannerz $\mathrm{H}$, Tuchsen F. Hospital admissions among male drivers in Denmark. Occup Environ Med 2001; 58:253-60.

2 Gustavsson P, Alfredsson L, Brunnberg H, et al. Myocardial infarction among male bus, taxi, and lorry drivers in middle Sweden. Occup Environ Med 1996;53:235-40.

3 Alfredsson L, Hammar N, Hogstedt C. Incidence of myocardial infarction and mortality from specific causes among bus drivers in Sweden. Int J Epidemiol 1993;22:57-61.

4 Bigert C, Gustavsson P, Hallqvist J, et al. Myocardial infarction among professional drivers. Epidemiology 2003;14:333-9.

5 Tuchsen F. Stroke morbidity in professional drivers in Denmark 1981-1990. Int J Epidemiol 1997;26:989-94.

6 Bigert C, Klerdal K, Hammar N, et al. Time trends in the incidence of myocardial infarction among professional drivers in Stockholm 1977-96. Occup Environ Med 2004;61:987-91.

7 Hedberg GE, Jacobsson KA, Janlert U, et al. Risk indicators of ischemic heart disease among male professional drivers in Sweden. Scand I Work Environ Health 1993; 19:326-33.

8 Hartvig P, Midttun $\mathrm{O}$. Coronary heart disease risk factors in bus and truck drivers. A controlled cohort study. Int Arch Occup Environ Health 1983;52:353-60.

9 Rosengren A, Anderson K, Wilhelmsen L. Risk of coronary heart disease in middle-aged male bus and tram drivers compared to men in other occupations: a prospective study. Int I Epidemiol 1991;20:82-7.

10 Belkic K, Emdad R, Theorell T. Occupational profile and cardiac risk: possible mechanisms and implications for professional drivers. Int $J$ Occup Med Environ Health 1998;11:37-57.

11 van der Beek AJ, Meijman TF, Frings-Dresen MH, et al. Lorry drivers' work stress evaluated by catecholamines excreted in urine. Occup Environ Med 1995;52:464-9.

12 Evans GW, Carrere S. Traffic congestion, perceived control, and psychophysiological stress among urban bus drivers. J Appl Psychol 1991;76:658-63.
13 Daleva M, Piperova-Dalbokova D, Hadjiolova I, et al. Changes in the excretion of corticosteroids and catecholamines in tractor-drivers. Int Arch Occup Environ Health 1982;49:345-52.

14 Bellet S, Roman L, Kostis J. The effect of automobile driving on catecholamine and adrenocortical excretion. Am J Cardiol 1969;24:365-8.

15 Sato S, Taoda K, Kawamura M, et al. Heart rate variability during long truck driving work. J Hum Ergol (Tokyo) 2001;30:235-40.

16 Egelund N. Spectral analysis of heart rate variability as an indicator of driver fatigue. Ergonomics 1982;25:663-72.

17 Libby P. Inflammation in atherosclerosis. Nature 2002;420:868-74.

18 Paramo JA, Orbe J. Hemostasis, inflammation and cardiovascular disease. Clin Lab 2002;48:463-70.

19 Ruberg FL, Leopold JA, Loscalzo J. Atherothrombosis: plaque instability and thrombogenesis. Prog Cardiovasc Dis 2002;44:381-94.

20 Chen JC, Dennerlein JT, Shih TS, et al. Knee pain and driving duration: a secondary analysis of the Taxi Drivers' Health Study. Am J Public Health 2004;94:575-81.

21 Chen JC, Chan WP, Katz JN, et al. Occupational and personal factors associated with acquired lumbar spondylolisthesis of urban taxi drivers. Occup Environ Med 2004;61:992-8.

22 Kannel WB, Anderson K, Wilson PW. White blood cell count and cardiovascular disease. Insights from the Framingham Study. Jama 1992;267:1253-6.

23 Lee CD, Folsom AR, Nieto FJ, et al. White blood cell count and incidence of coronary heart disease and ischemic stroke and mortality from cardiovascular disease in African-American and White men and women: atherosclerosis risk in communities study. Am J Epidemiol 2001;154:758-64.

24 Hasegawa T, Negishi T, Deguchi M. WBC count, atherosclerosis and coronary risk factors. J Atheroscler Thromb 2002:9:219-23.

25 Irace C, Ciamei M, Crivaro A, et al. Hematocrit is associated with carotid atherosclerosis in men but not in women. Coron Artery Dis 2003;14:279-84.

26 Thaulow E, Erikssen J, Sandvik L, et al. Blood platelet count and function are related to total and cardiovascular death in apparently healthy men. Circulation 1991:84:613-17.

27 Pearson TA, Mensah GA, Alexander RW, et al. Markers of inflammation and cardiovascular disease: application to clinical and public health practice: A statement for healthcare professionals from the Centers for Disease Control and Prevention and the American Heart Association. Circulation 2003;107:499-511

28 Wiktorin $C$, Vingard E, Mortimer M, et al. Interview versus questionnaire for assessing physical loads in the population-based MUSIC-Norrtalie Study. Am J Ind Med 1999;35:441-55.

29 Palmer KT, Haward B, Griffin MJ, et al. Validity of self reported occupational exposures to hand transmitted and whole body vibration. Occup Environ Med 2000; $57: 237-41$

30 Chen JC, Chang WR, Shih TS, et al. Using exposure prediction rules for exposure assessment: an example on whole-body vibration in taxi drivers. Epidemiology 2004;15:293-9.

31 DOH. Taiwan Health News: Dietary Guides Help Maintain Healthy Life. Special Edition. Taiwan: Department of Health (DOH), Executive Yuan, 2004, Available at http://www.doh.gov.tw/dohenglish/Media/SE200405142.asp (accessed 15 September 2005).

32 Cheng Y, Luh WM, Guo YL. Reliability and validity of the Chinese version of the Job Content Questionnaire in Taiwanese workers. Int I Behav Med 2003;10:15-30.

33 Barron HV, Harr SD, Radford MJ, et al. The association between white blood cell count and acute myocardial infarction mortality in patients $\geqslant 65$ years of age: findings from the cooperative cardiovascular project. J Am Coll Cardiol 2001;38:1654-61

34 Cannon CP, McCabe CH, Wilcox RG, et al. Association of white blood cell count with increased mortality in acute myocardial infarction and unstable angina pectoris. OPUS-TIMI 16 Investigators. Am J Cardiol. 2001;87: 636-9, A10).

35 Fransson E, De Faire U, Ahlbom A, et al. The risk of acute myocardial infarction: interactions of types of physical activity. Epidemiology 2004; 15:573-82.

36 Kannel WB, Belanger A, D'Agostino R, et al. Physical activity and physical demand on the job and risk of cardiovascular disease and death: the Framingham Study. Am Heart J 1986;112:820-5.

37 Black PH, Garbutt LD. Stress, inflammation and cardiovascular disease. J Psychosom Res 2002;52:1-23.

38 Mattiasson I, Lindgarde F. The effect of psychosocial stress and risk factors for ischaemic heart disease on the plasma fibrinogen concentration. J Intern Med 1993;234:45-51

39 Schwartz J. Air pollution and blood markers of cardiovascular risk. Environ Health Perspect 2001;109(Suppl 3):405-9.

40 Liao D, Heiss G, Chinchilli VM, et al. Association of criteria pollutants with plasma hemostatic/inflammatory markers: a population-based study. J Expo Anal Environ Epidemiol 2005;15:319-28.

41 Nieto FJ, Szklo M, Folsom AR, et al. Leukocyte count correlates in middle-aged adults: the Atherosclerosis Risk in Communities (ARIC) Study. Am J Epidemiol 1992;136:525-37.

42 Noguchi T, Tsujisaki M, Imai K, et al. Relationship among risk factors of atherosclerosis, leukocyte count, and soluble intercellular adhesion molecule1. Intern Med 1998:37:123-6.

43 DOH. Statistics and Analyses: Key Indicators of Health Statistics. Taiwan: Department of Health (DOH), Executive Yuan, 2004, Available at http:// www.doh.gov.tw/EN/Webpage/index.aspx\# (accessed 15 September 2005).

44 Liang W-M, Kuo H-W, Wang C-B. Prevalence of tobacco smoking, drinking and betel nut chewing among Taiwanese workers in 1999. Mid Taiwan J Med 2002;7:146-54. 